\title{
Efeito da adição de lignina kraft proveniente da madeira de eucalipto na reologia do CAP 50/70
}

\author{
Effect of the addition of kraft lignin from \\ eucalyptus wood in the rheology \\ of a CAP $50 / 70$
}

Nataliene Silva dos Santos ${ }^{1}$, John Kennedy Guedes Rodrigues ${ }^{2}$, Ana Maria Gonçalves Duarte Mendonça ${ }^{2}$

\footnotetext{
${ }^{1}$ Laboratório de Engenharia de Pavimentos - DEC/CTRN CEP: 58429-900, Campina Grande, PB, Brasil. e-mail: natalienesslim@hotmail.com

${ }^{2}$ Laboratório de Engenharia de Pavimentos - DEC/CTRN CEP: 58429-900, Campina Grande, PB, Brasil. e-mail: profkennedy@hotmail.com; ana.mendonca@gmail.com
}

\section{RESUMO}

O estudo e o desenvolvimento de novas tecnologias de materiais para pavimentação tem crescido bastante motivados pelos diversos problemas que os pavimentos têm enfrentado. Atualmente os polímeros sintéticos já ocuparam seu lugar no mercado pela eficiência que apresentaram em diversos estudos e quando testados em serviço. No entanto, a dependência por combustíveis fósseis é preocupante, principalmente pelo impacto ambiental resultante de tal utilização. Sendo assim, alternativas baseadas em recursos renováveis e ainda aproveitados de processos industriais vem ganhado espaço. A lignina é um polímero natural, subproduto da indústria de papel e celulose, extraída da madeira na forma de um licor negro por diversos processos, sendo o processo kraft o principal e mais utilizado. Esse material já demostrou grande potencial em algumas pesquisas a partir de sua associação com o ligante asfáltico, principalmente por apresentar propriedades antioxidantes. Assim, essa pesquisa tem como objetivo a verificação do efeito da adição de lignina em teores de 3\%, 6\% e 9\% nas propriedades reológicas do ligante asfáltico convencional CAP 50/70, antes e após o envelhecimento a curto prazo (RTFO). Foram realizados ensaios convencionais de penetração, ponto de amolecimento e recuperação elástica, além de ensaios especiais como viscosidade rotacional e os realizados no DSR, para a determinação dos parâmetros do grau de desempenho, $\mathrm{G}^{*}, \delta$ e $\mathrm{G}^{*} / \mathrm{sen} \delta$, além da \%Rec e Jnr, estes últimos através do MSCR. Verificou-se que os ligantes modificados por adição de lignina se apresentaram mais resistentes à variação de temperatura, à deformação permanente, mas principalmente ao envelhecimento, mostrando a atuação desse material como antioxidante, especialmente para o teor de $9 \%$, embora os demais teores também tenham apresentado desempenho superior ao ligante puro, comprovando que a utilização da lignina, de um modo geral, se mostrou viável reológica e ambientalmente ao ser associada ao ligante convencional.

Palavras-chave: Ligante asfáltico. Lignina. Envelhecimento. Propriedades reológicas.

\section{ABSTRACT}

The study and development of new technologies for paving materials has been greatly motivated by the many problems that pavements have faced. Currently synthetic polymers have already taken their place in the market for the efficiency they have presented in several studies and when tested in service. However, this dependence on fossil fuels is of concern, mainly because of the environmental impact resulting from such use. Thus, alternatives based on renewable resources and still taken advantage of industrial processes have gained space. Lignin is a natural polymer, a byproduct of the pulp and paper industry, extracted from wood in the form of a black liquor by various processes, the kraft process being the main and most used. This material has already demonstrated great potential in some researches due to its association with the asphalt binder, mainly because it has antioxidant properties. Thus, this research aimed to verify the effect of the addition of lignin at 3\%,6\% and 9\% in the rheological properties of a conventional asphalt binder CAP 50/70 before and after the short term aging (RTFO). Conventional tests of penetration, softening point and elastic recovery were carried out in addition to special tests such as rotational viscosity and those performed in the DSR, in 
order to determine the parameters of the degree of performance, $\mathrm{G}^{*}, \delta$ and $\mathrm{G}^{*} / \sin \delta$, in addition to $\%$ Rec and Jnr, the latter through the MSCR. It was found that the binders modified by addition of lignin were more resistant to temperature variation, to permanent deformation, but mainly to aging, showing the performance of this material as an antioxidant, especially for the $9 \%$ content, although the other contents also have shown superior performance to the pure binder, proving that the use of lignin in general has proved to be viable both rheologically and environmentally when it is associated with the conventional binder.

Keywords: Asphalt binder. Lignin. Aging. Rheological properties.

\section{INTRODUÇÃO}

A malha viária brasileira, assim como de outros países, carece constantemente de avaliação e renovação devido à deterioração dos pavimentos, notadamente dos pavimentos asfálticos. Os defeitos desencadeados tem origem no mau uso da via devido a grandes solicitações para as quais o pavimento não foi projetado, na má execução do processo construtivo, no emprego de materiais com propriedades insuficientes para atender à necessidade, nas condições climáticas atuantes [1], entre outras causas.

Sendo assim, cada vez mais são indispensáveis soluções e desenvolvimento de tecnologias de materiais para pavimentação. É nesse contexto que surgem os asfaltos modificados e como alternativa para melhoria das propriedades dos Cimentos Asfálticos de Petróleo (CAP), a modificação por polímeros tem se mostrado eficaz em vários estudos que vem sendo realizados $([2,3,4,5,6])$ e quando em serviço. Os polímeros mais usuais são os polímeros SBS (copolímero de estireno e butadieno), polietileno, SBR (borracha de estireno-butadieno), borracha de pneu moído e EVA (copolímero de etileno e acetato de vinila) [3]. Dessa forma, aliado à busca por modificadores de ligantes asfálticos surge em paralelo o conceito de sustentabilidade e isso vem abrindo espaço para tecnologias com a utilização de modificadores naturais e reaproveitados de processos industriais.

$\mathrm{Na}$ literatura é possível encontrar pesquisas com produtos naturais associados ao ligante como óleos vegetais de mamona, linhaça, algodão, dendê, soja, milho e moringa ([7,8,9,10]), "fibras de biomassa, lodos, asfalto natural e enxofre" [7], além de estudos pioneiros com lignina, entre outros.

A lignina é um subproduto da indústria de papel e celulose, sendo obtida através desta em maior escala com geração de milhões de toneladas a cada ano. Pode ser extraída nos diversos processos de polpação da madeira, sendo o Processo Kraft (reação da madeira com hidróxido de sódio + sulfeto de sódio) o mais usual no contexto industrial brasileiro, onde $81 \%$ do processamento da madeira é realizado dessa maneira [11].

Júnior e Colodette [12] citam que esse setor industrial está passando por uma evolução no que diz respeito à produção, deixando de produzir apenas papel e celulose, mas também proporcionando um maior aproveitamento da toda a matéria-prima a partir da consideração de seus derivados, como a lignina recuperada durante o processo, para fabricação de outros produtos. Piló-Veloso et al. [13] já enfatizava o potencial de um emprego mais nobre para a lignina, além de sua utilização como fonte de energia através da queima desse material, que até hoje ainda é o seu principal aproveitamento [14].

Partindo-se dessa afirmação, quando parte da lignina extraída no processo de fabricação de papel não está sendo utilizada na queima para aproveitamento energético na própria indústria, por ainda restar um excedente [14] esse material ainda é descartado, o que vem despertando interesse em mais alternativas para sua aplicação, além de que essa saída pode implicar em fonte de renda extra para os próprios fabricantes de papel.

A lignina possui estrutura relativamente semelhante do ponto de vista macromolecular aos componentes do CAP [5] e assim como ocorre com a associação dos demais polímeros com o ligante, em que é crucial a compatibilidade entre ambos para se obter melhores desempenhos, esse material poderá também trazer melhorias ao asfalto convencional no que diz respeito às suas propriedades reológicas.

Sobreiro [5] afirma que o conceito de reologia como "estudo da deformação e fluxo da matéria" foi introduzido desde 1929 pela Sociedade Americana de Reologia. Esse "fluxo e deformação" são provocados pela aplicação de tensões. Os pavimentos asfálticos, quando em serviço, são submetidos a tensões, deformações e fatores ambientais diversos [15] para os quais visando minimizar seus efeitos, segundo Mothé [16], torna-se indispensável o conhecimento das propriedades reológicas do asfalto (viscosidade, rigidez e elasticidade), que são influenciadas também por alterações em sua composição química [4]. É desejável, no geral, que os ligantes não sejam muito viscosos nem tão rígidos ou quebradiços a baixas temperaturas, possuam comportamento visco-elástico à temperatura ambiente e fluidez a altas temperaturas; um alto módulo de cisalhamento complexo $\mathrm{G}^{*}$, o que acarreta em maior rigidez e consequente maior resistência à deformação; e um menor ângulo de fase $\delta$, que representa uma maior resposta elástica [15,17].

A importância desse estudo é também de minimizar gastos na produção do asfalto modificado, pelo provável baixo custo da lignina comparado ao custo de polímeros usuais; torná-lo mais sustentável, por ser a lignina um material renovável; evitar a má disposição do material como resíduo da fabricação de papel e assim não comprometer ainda mais a vida útil dos aterros sanitários. 
Assim, este trabalho tem como objetivo principal analisar o efeito da adição de lignina nas propriedades reológicas do ligante asfáltico convencional CAP 50/70, antes e após o envelhecimento a curto prazo (RTFO).

\section{MATERIAIS E MÉTODOS}

Os materiais utilizados para realização deste trabalho foram: Cimento Asfáltico de Petróleo - CAP 50/70, lignina da madeira resultante de um cruzamento genético entre a Eucalyptus grandis e a Eucalyptus urophilla, extraída por meio do processo Kraft.

Foram realizados ensaios convencionais para caracterização do CAP puro e do CAP modificado pela adição de lignina em teores de 3\%, 6\% e 9\%, antes e após envelhecimento a curto prazo - RTFO. Dentre eles: o ensaio de penetração, que determina a consistência do ligante asfáltico através da medida da profundidade, em décimos de milímetro, que uma agulha de massa padronizada ( $100 \mathrm{~g})$ penetra verticalmente numa amostra de $\mathrm{CAP}$, por 5 segundos, à temperatura de $25^{\circ} \mathrm{C}$. O procedimento é regido pela norma DNITME 155/2010[18]; o ensaio de ponto de amolecimento, também conhecido por anel e bola, regido pela norma DNIT-ME 131/2010[19]; e o ensaio de recuperação elástica, que é a medida da capacidade de retorno do asfalto quando a tração mecânica aplicada no corpo-de-prova a $25^{\circ} \mathrm{C}$ é interrompida. $\mathrm{O}$ procedimento foi realizado de acordo com a norma DNIT-ME 130/2010[20]. Ensaios especiais, como: viscosidade rotacional, que é utilizado para medir a viscosidade do asfalto a altas temperaturas, $135^{\circ} \mathrm{C}, 150{ }^{\circ} \mathrm{C}$ e $177{ }^{\circ} \mathrm{C}$, conforme a ABNT NBR 15184/2004 [21] e a ASTM D4402-15 [22], e contribui significativamente na definição das temperaturas de usinagem e compactação do asfalto. O viscosímetro rotacional utilizado foi o Brookfield, modelo DV-III ULTRA, acoplado a um controlador de temperatura THERMOSEL.

Ensaios reológicos no reômetro de cisalhamento dinâmico (DSR) para a determinação de parâmetros, dentre eles: o Módulo complexo $\left(\mathrm{G}^{*}\right)$ e o Ângulo de fase $(\delta)$, indicadores da rigidez e da elasticidade, respectivamente, além da máxima temperatura do Grau de desempenho (PG), importante no controle da rigidez do asfalto a altas temperaturas. O procedimento para obtenção de tais parâmetros é o mesmo: é realizada uma varredura de temperaturas na faixa de 46 a $82^{\circ} \mathrm{C}$, variando de 6 em $6^{\circ} \mathrm{C}$, conforme estipula a ASTM D6373 - 15 [23], numa frequência de $10 \mathrm{rad} / \mathrm{s}$ e deformação de $10 \%$ nas amostras antes e após o envelhecimento RTFO. Outro teste realizado no reômetro foi o de fluência e recuperação sob tensões múltiplas (MSCR), através da norma ASTM D7405-15 [24], utilizando a temperatura máxima do PG do ligante envelhecido. São realizados 20 ciclos de 10 segundos, onde nos 10 primeiros são aplicadas uma tensão de $100 \mathrm{~Pa}$ (tráfego normal) e nos outros 10, uma tensão de 3,2 kPa (tráfego intenso). Em cada ciclo, a tensão foi aplicada em 1 segundo e relaxada nos 9 segundos restantes. Como resultado do teste tem-se os parâmetros, Jnr e \% Rec, indicadores mais fiéis da deformação permanente do asfalto. Os ensaios reológicos foram realizados utilizando-se um reômetro de cisalhamento dinâmico, modelo Discovery Hybrid Rheometer - DHR 1.

\section{RESULTADOS}

O envelhecimento a curto prazo simula o processo oxidativo do ligante asfáltico provocado pela usinagem, aplicação e compactação da mistura asfáltica. Como resultado, o procedimento nos fornece a variação da perda de massa das amostras submetidas, além deste ser pré-requisito para os demais ensaios que precisam prever o comportamento dos materiais também sob esta condição de envelhecimento.

A perda de massa das amostras de ligante significa o quanto o material sofreu o efeito da ação do calor e do ar aplicados no processo, ao ponto de causar a degradação e redução de parte da matéria presente, o que implica em alterações na composição e nas propriedades reológicas do material, como o aumento de sua viscosidade e rigidez [1]. A Figura 1 ilustra os resultados de perda de massa (\%) dos ligantes puro e modificados por adição de lignina após o envelhecimento comparados ao limite estabelecido pela Agência Nacional do Petróleo, Gás Natural e Biocombustíveis (ANP). 


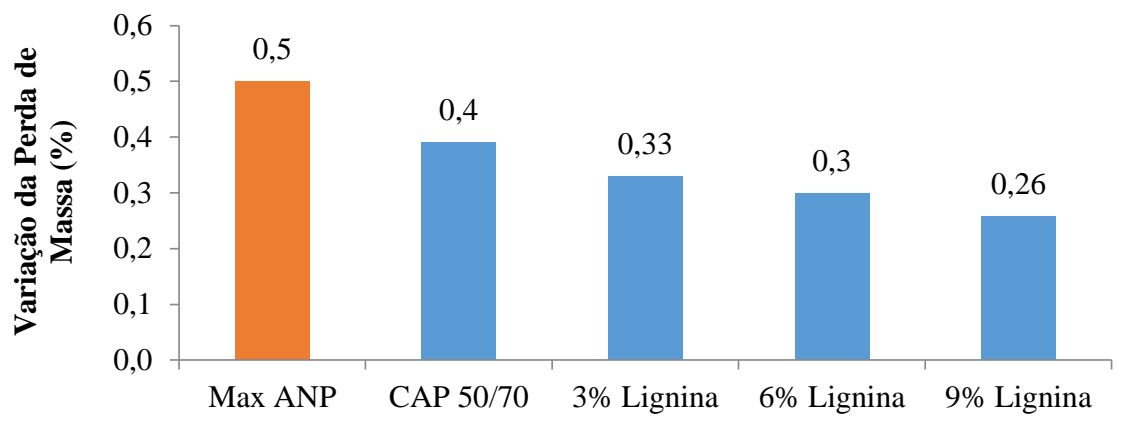

Figura 1: Perda de massa (\%) dos ligantes puro e modificados por adição de lignina após o envelhecimento.

$\mathrm{O}$ ensaio de penetração determina a consistência do ligante à temperatura de $25^{\circ} \mathrm{C}$ e o parâmetro penetração está diretamente relacionado à propriedade de rigidez do pavimento. A Figura 2 ilustra os resultados da penetração das amostras antes e após o envelhecimento e foi determinada a partir da média de cinco leituras em cada amostra.

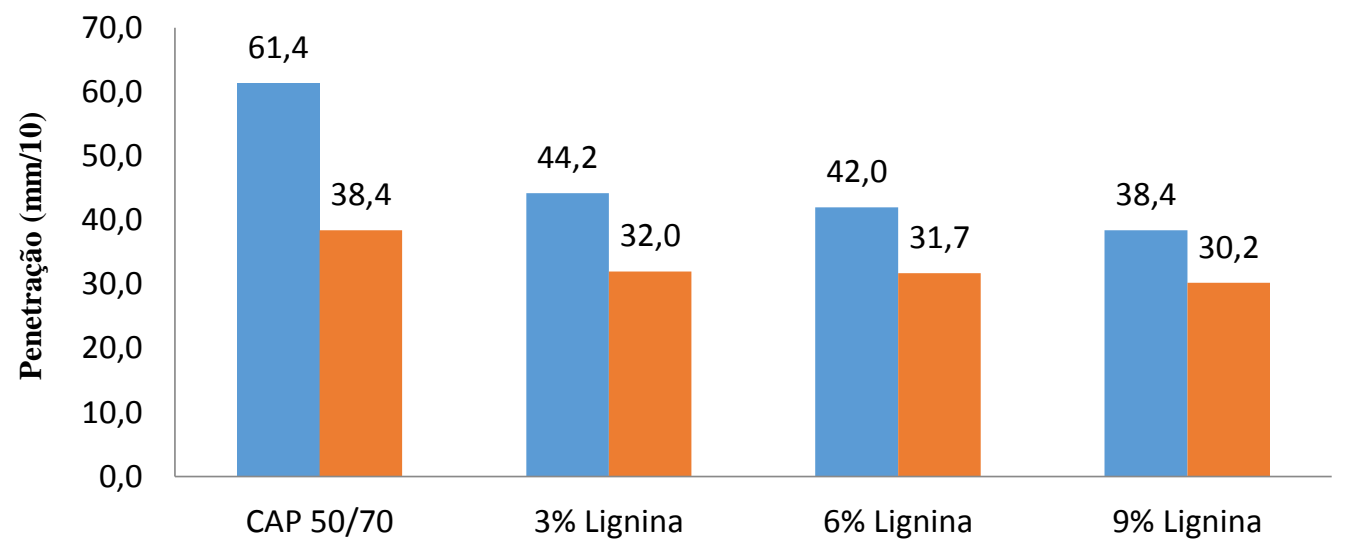

Figura 2: Penetração do ligante asfáltico puro e modificado por adição de lignina antes e após o envelhecimento-RTFO.

Os resultados dos ligantes modificados por adição de lignina superaram o CAP 50/70, seguindo uma tendência de que quanto maior o teor de lignina maior a Porcentagem de penetração retida - PPR, o que tornou o ligante mais resistente ao envelhecimento e mostrou positivamente que a variação da rigidez, nestes casos, foi menor. Os resultados da PPR estão ilustrados na Figura 3.

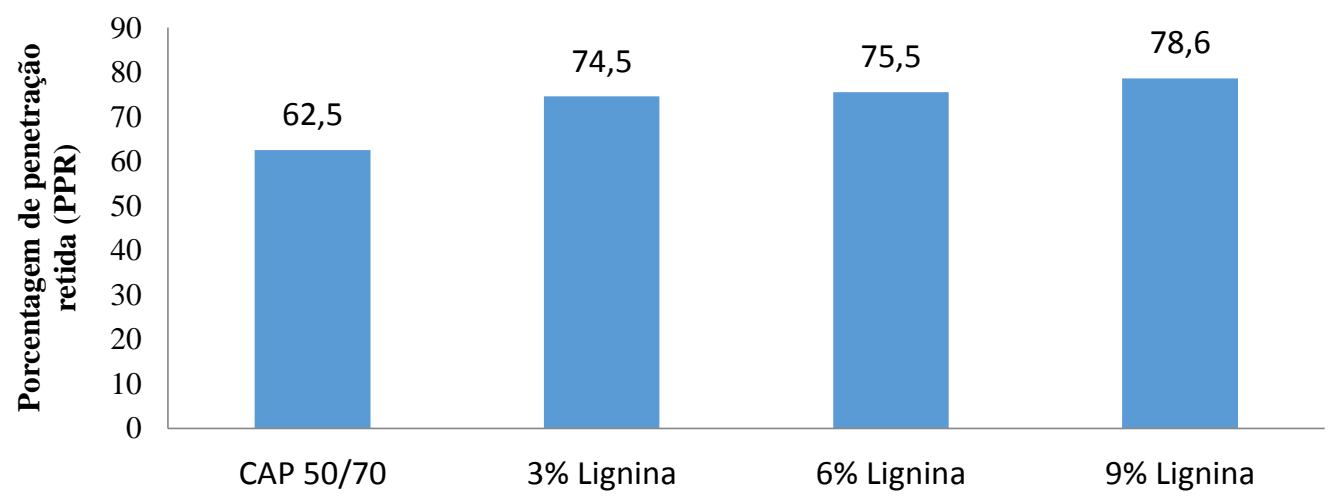

Figura 3: Porcentagem de penetração retida (PPR).

A determinação do ponto de amolecimento é mais uma medida empírica da consistência do ligante e consiste em definir uma temperatura de referência para a qual o ligante atinge certa condição de escoamento. Este parâmetro relaciona-se à manutenção das propriedades do ligante a elevadas temperaturas e ao aumento 
da resistência à deformação permanente. Foram obtidos da média de duas temperaturas e na Figura 4 podem ser observados os resultados do ensaio.

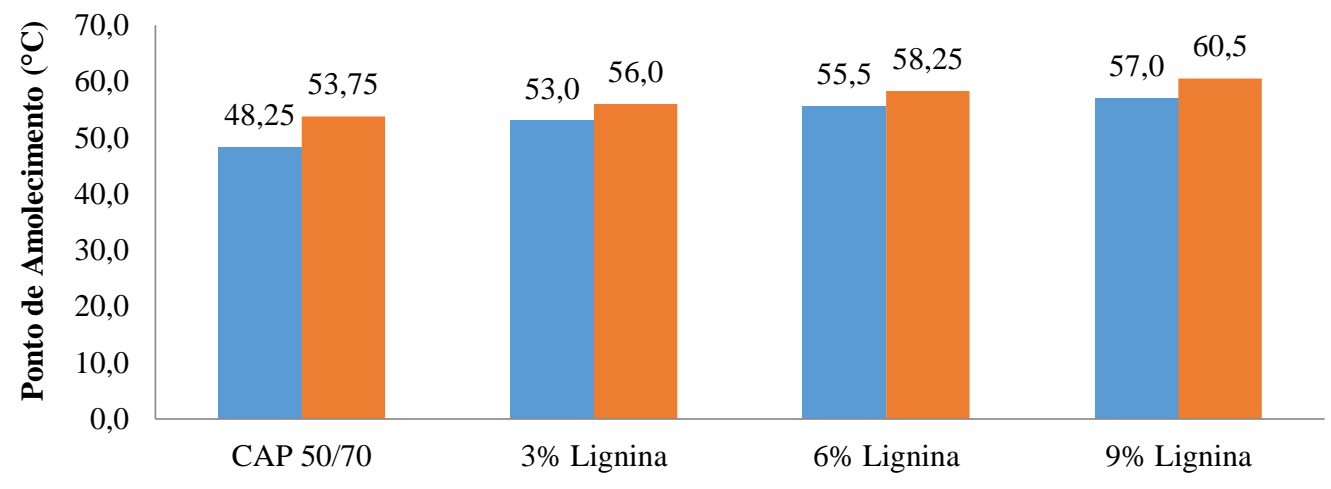

Figura 4: Ponto de amolecimento dos ligantes puro e modificados por adição de lignina.

A resolução ANP no 19/2005 [25] estabelece a temperatura mínima de $46^{\circ} \mathrm{C}$ para o ponto de amolecimento na condição normal, e dessa forma, verifica-se que todos os ligantes apresentaram resultados que satisfazem os limites estabelecidos. Após o envelhecimento, esse parâmetro é limitado a uma variação de no máximo $8^{\circ} \mathrm{C}$ comparado ao ligante sem envelhecimento. A figura 5 ilustra os resultados que comprovam o enquadramento ao que prescreve a especificação.

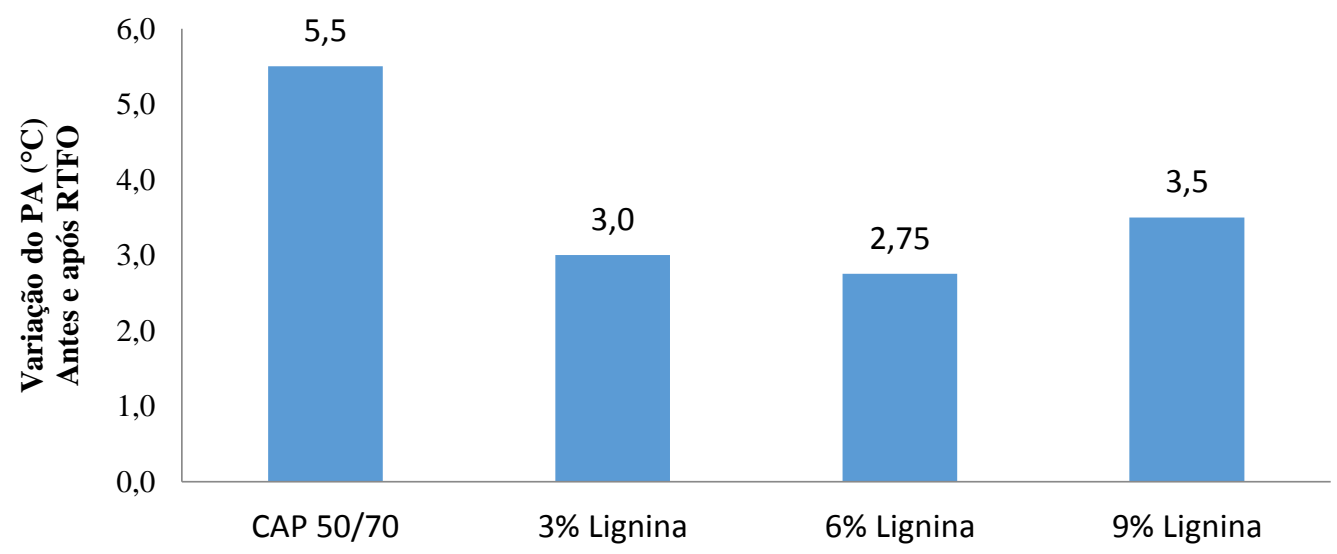

Figura 5: Variação do ponto de amolecimento (PA) antes e após o RTFO.

O Índice de Susceptibilidade Térmica (IST), que indica a sensibilidade do ligante à variação de temperatura, é obtido a partir dos resultados de penetração e ponto de amolecimento. A especificação da ANP define a faixa para enquadramento do CAP 50/70 variando de $(-1,5)$ a $(0,7)$ para este índice. A tabela 1 apresenta os resultados do IST para o ligante puro e modificados por adição de lignina.

Tabela 1: Índice de Susceptibilidade Térmica.

\begin{tabular}{cc}
\hline AMOSTRA & IST \\
\hline CAP 50/70 & $-1,17$ \\
3\% Lignina & $-0,75$ \\
6\% Lignina & $-0,29$ \\
9\% Lignina & $-0,10$ \\
\hline
\end{tabular}

Segundo Gama [26] ligantes puros apresentam recuperação elástica muito reduzida, no entanto, podendo ser elevada até $90 \%$ com o acréscimo de polímeros com características elastoméricas. A Figura 6 ilustra os resultados da recuperação elástica do ligante puro e modificado por adição de lignina, antes e após envelhecimento a curto prazo - RTFO. 


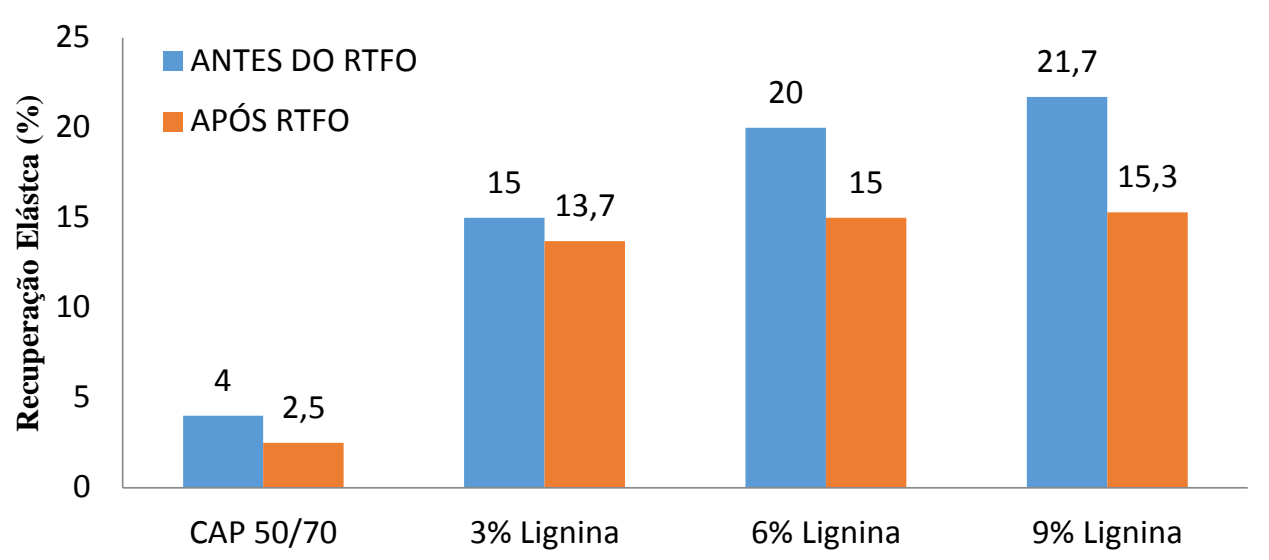

Figura 6: Recuperação elástica do ligante puro e modificado por adição de lignina, antes e após envelhecimento a curto prazo - RTFO.

A viscosidade do ligante influencia sua capacidade em envolver-se com os agregados da mistura e a sua trabalhabilidade em campo, além de ser possível determinar as temperaturas necessárias na usinagem e compactação. Por isso, seu estudo tem fundamental importância, visto que uma alta viscosidade conduz a necessidade de altas temperaturas nas etapas da pavimentação, o que pode até inviabilizar o uso do material. A Figura 7 ilustra o comportamento que os ligantes apresentaram quando submetidos ao viscosímetro Brookfield.

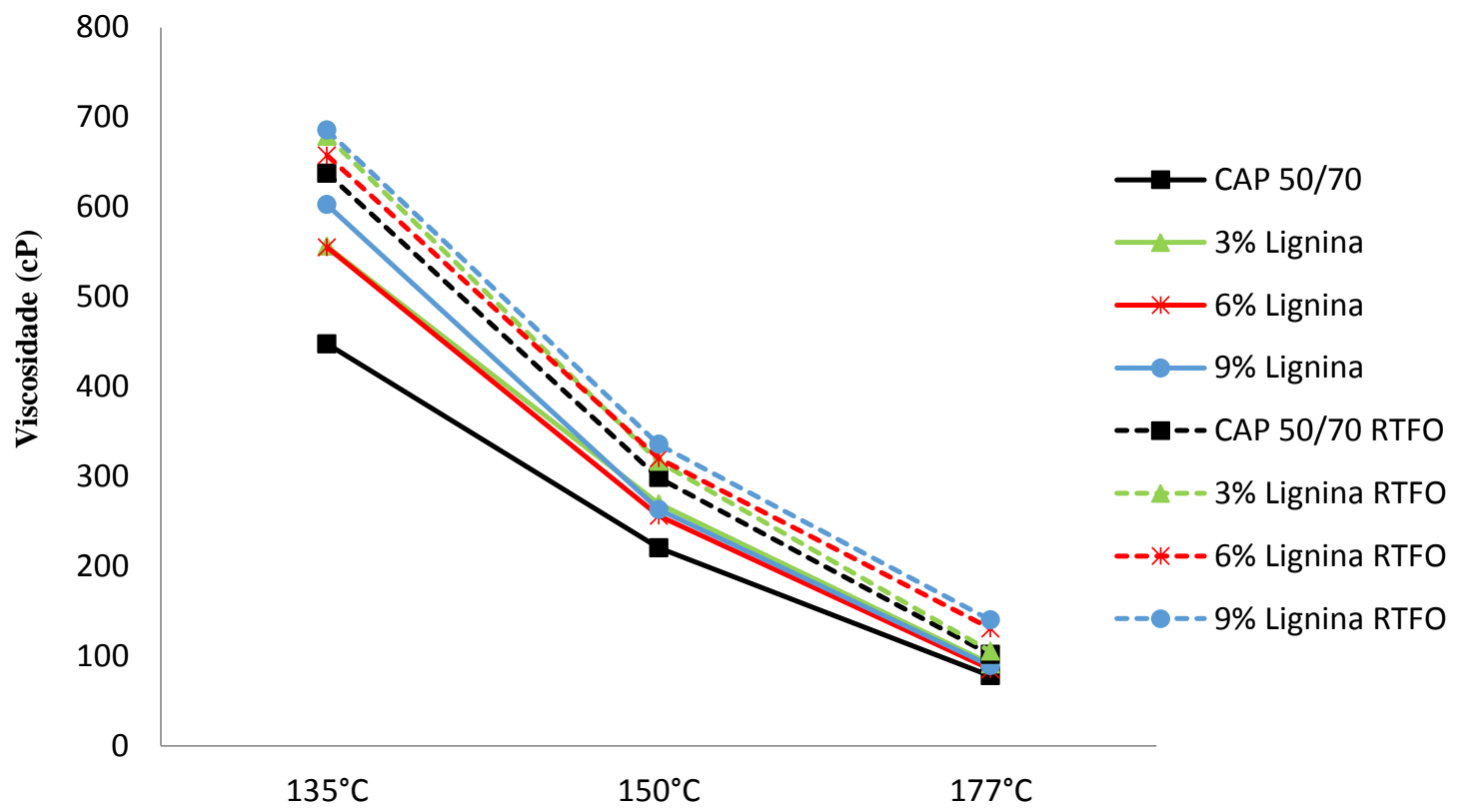

Figura 7: Viscosidade dos ligantes antes e após RTFO.

Para os ensaios realizados no reômetro foram definidos os parâmetros reológicos para o ligante puro e modificados por adição de lignina, antes e após RTFO, tais como o Grau de desempenho, o Módulo Complexo e o Ângulo de fase, além do parâmetro $G^{*} /$ sen $\delta$. Na figura 8 estão ilustrados os resultados de PG dos ligantes antes e após RTFO. 


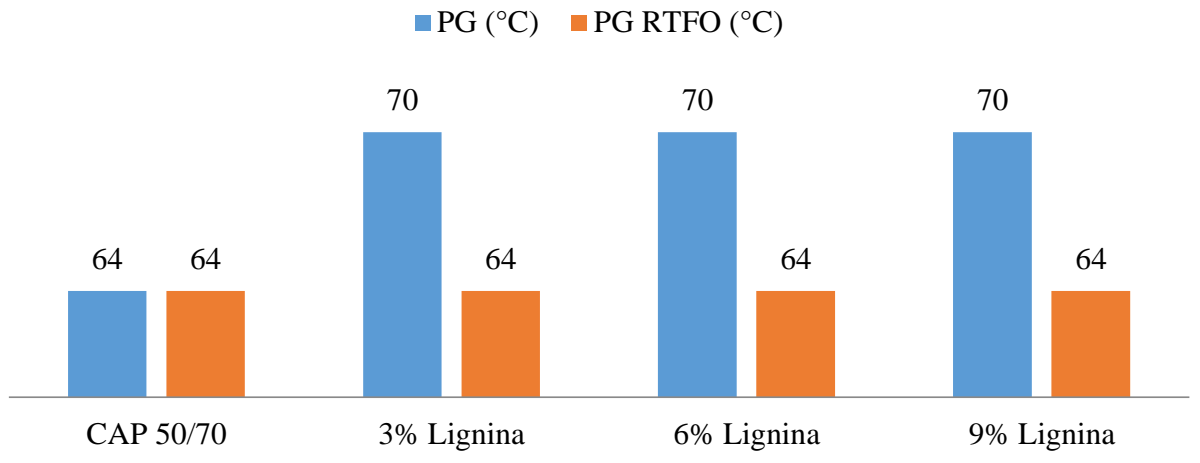

Figura 8: Grau de desempenho máximo dos ligantes.

Vale salientar que o PG é determinado tendo como limitantes o valor mínimo do parâmetro G*/sen $\delta$ de $1 \mathrm{kPa}$ antes do RTFO e 2,2 kPa após RTFO, segundo a especificação SUPERPAVE. Na Figura 9 e Figura 10 , estão ilustrados o comportamento do parâmetro $\mathrm{G}^{*} / \operatorname{sen} \delta$, antes e após envelhecimento a curto prazo RTFO, respectivamente, que além de ser um indicador da temperatura do Grau de desempenho propriamente dito, representa a resistência à deformação em termos da elasticidade do ligante.

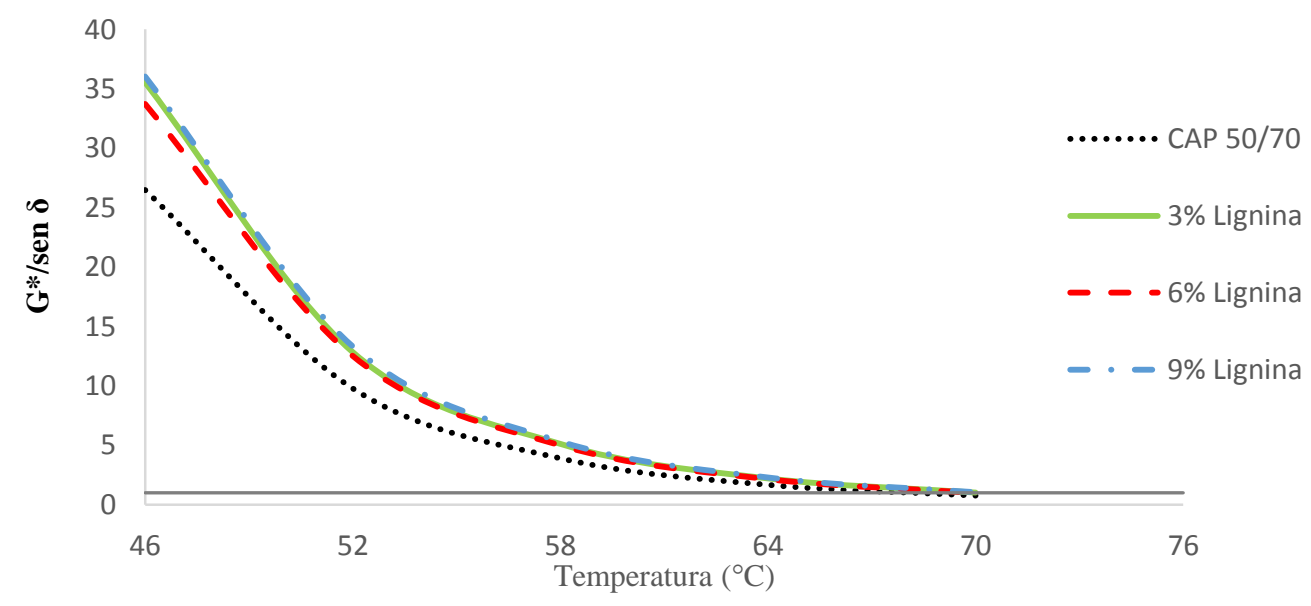

Figura 9: Parâmetro $G^{*} / \operatorname{sen} \delta$ antes do envelhecimento a curto prazo-RTFO.

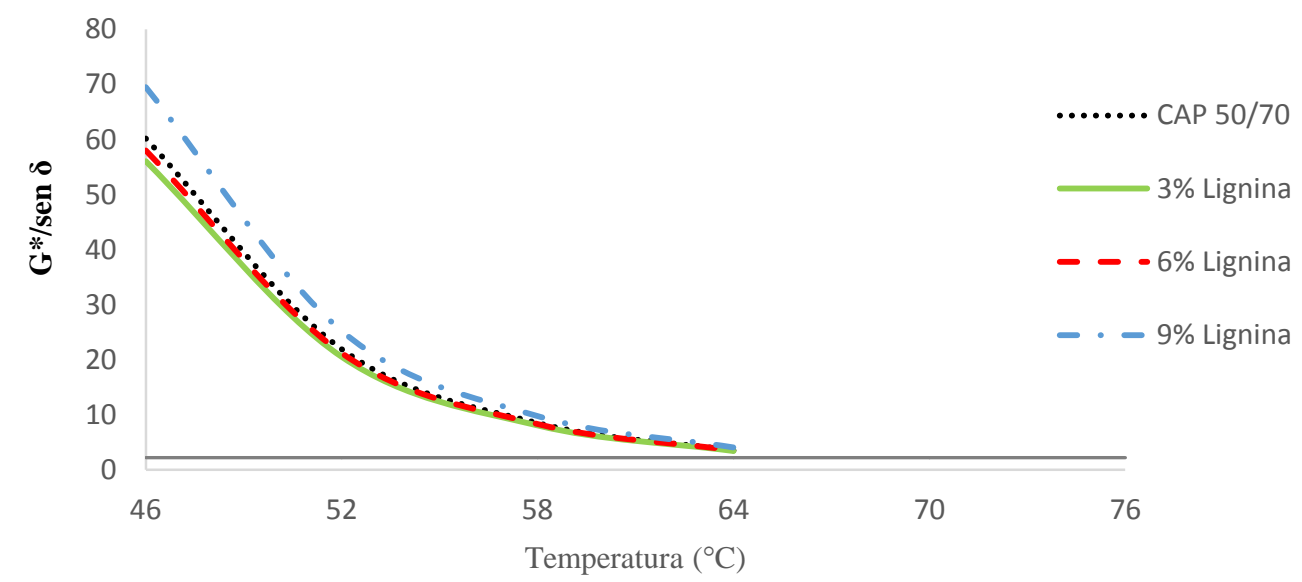

Figura 10: Parâmetro G*/sen $\delta$ após envelhecimento a curto prazo-RTFO.

Os ângulos de fase dos ligantes modificados por adição de lignina se mostraram inferiores comparados ao do ligante puro e essa diferença implica em uma pequena melhoria no comportamento 
elástico. A Figura 11 ilustra os ângulos de fase do ligante puro e modificado por adição de lignina antes do envelhecimento a curto prazo-RTFO.

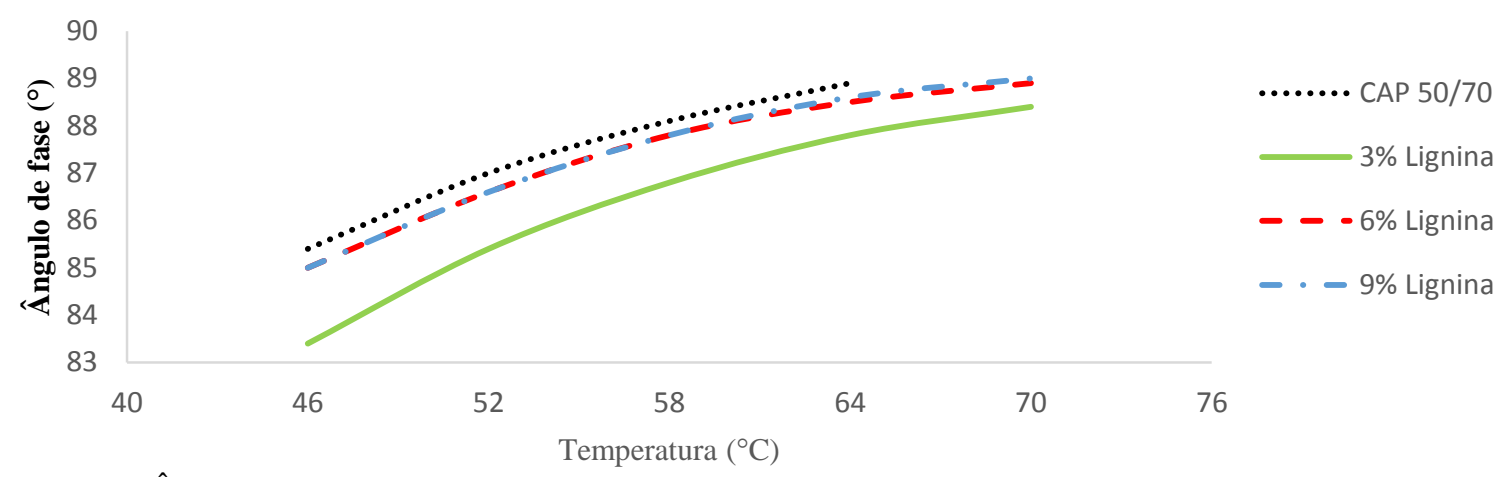

Figura 11: Ângulo de fase do ligante puro e modificado por adição de lignina antes do envelhecimento a curto prazo-RTFO.

Para os ângulos de fase do ligante após RTFO, obteve-se $\delta$ inferiores à curva do ligante puro. A figura 12 ilustra o ângulo de fase do ligante puro e modificado por adição de lignina após do envelhecimento a curto prazo-RTFO.

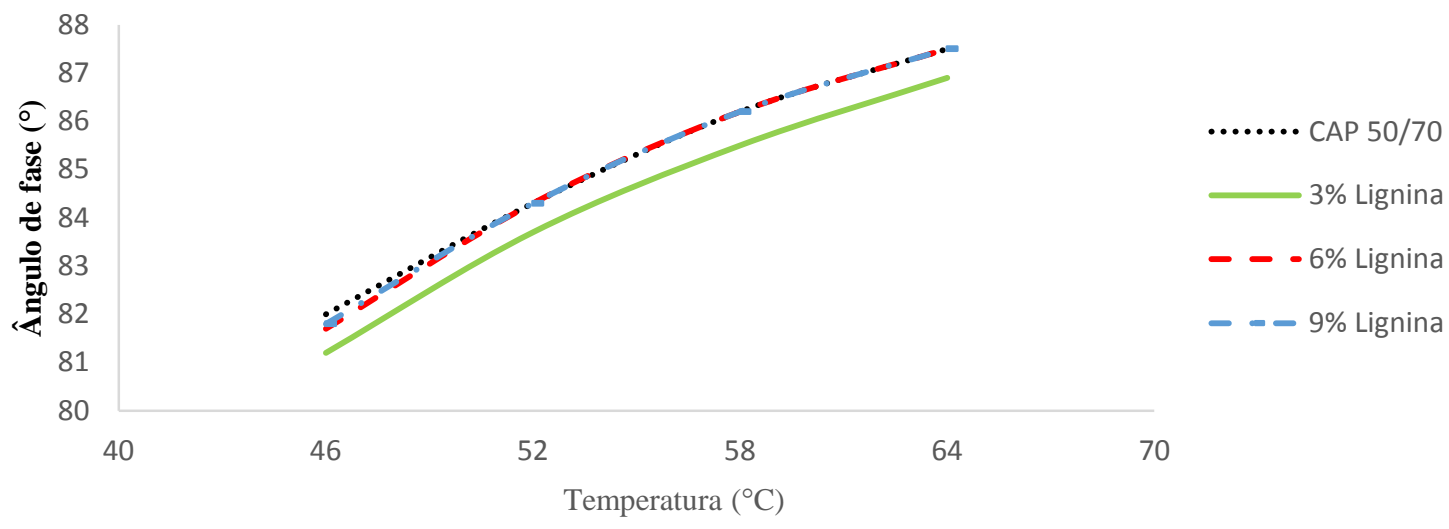

Figura 12: Ângulo de fase do ligante puro e modificado por adição de lignina após do envelhecimento a curto prazo-RTFO.

O teste de Fluência e Recuperação sob tensões Múltiplas fornece dois parâmetros mais adequados para indicar a resistência à deformação permanente do material, representados pelo percentual de recuperação (\% Rec) e a compliância não-recuperável (Jnr). Na Tabela 2 são mostrados os resultados desses parâmetros, além da diferença percentual entre as compliâncias não-recuperáveis (Jnr dif), que indica a sensibilidade da deformação do ligante ao aumento do nível de tensão.

Tabela 2: Parâmetros obtidos no teste de fluência e recuperação.

\begin{tabular}{|c|c|c|c|c|c|c|}
\hline \multirow{2}{*}{$\begin{array}{c}\text { PG } \\
\text { RTFO } \\
\left({ }^{\circ} \mathbf{C}\right)\end{array}$} & \multirow[t]{2}{*}{ AMOSTRA } & \multicolumn{2}{|c|}{$\begin{array}{c}\text { PERCENTUAL DE } \\
\text { RECUPERAÇÃO (\%) }\end{array}$} & \multicolumn{2}{|c|}{$\begin{array}{c}\text { COMPLIÂNCIA NÃO- } \\
\text { RECUPERÁVEL JNR }\left(\mathrm{kPa}^{-1}\right)\end{array}$} & \multirow[t]{2}{*}{ Jnr dif $(\%)$} \\
\hline & & $100 \mathrm{~Pa}$ & $3200 \mathrm{~Pa}$ & $100 \mathrm{~Pa}$ & $3200 \mathrm{~Pa}$ & \\
\hline 64 & CAP 50/70 & 1,8 & 0,5 & 4,5 & 4,9 & 9,1 \\
\hline 64 & $3 \%$ Lignina & 2,2 & 0,6 & 2,5 & 2,6 & 4,5 \\
\hline 64 & $6 \%$ Lignina & 1,0 & 0,3 & 2,5 & 2,6 & 3,7 \\
\hline 64 & $9 \%$ Lignina & 0,9 & 0,3 & 2,3 & 2,4 & 3,2 \\
\hline
\end{tabular}


A figura 13 ilustra os resultados da compliância não-recuperável obtida para o ligante puro e modificado por adição de lignina.

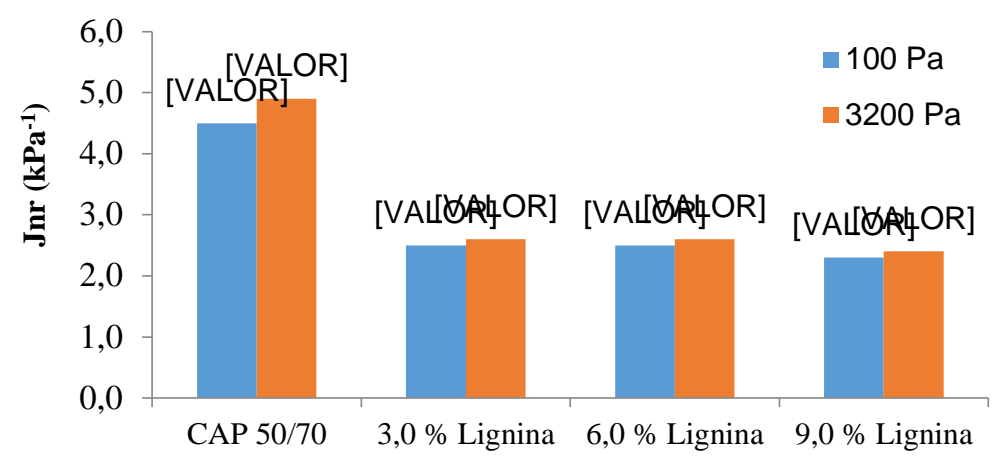

Figura 13: Compliância não-recuperável para o ligante puro e modificado por adição de lignina.

\section{DISCUSSÃO}

As perdas de massa para as amostras modificadas com a adição de lignina foram menores comparadas à perda do ligante puro e observa-se uma tendência inversamente proporcional, pois quanto maior o teor de lignina menor foi à perda. Isto significa uma menor susceptibilidade ao envelhecimento causada pela presença da lignina no ligante. Apesar da variação não ter sido tão ampla, a adição de teores de lignina resultou em manter um pouco mais as propriedades do ligante sujeito à oxidação e temperatura elevada.

Cravo [1] cita que o envelhecimento pode ser prejudicial ou benéfico desde que o enrijecimento causado tenha um certo limite, pois quando excessivo, pode levar a trincas térmicas e por fadiga e, quando na medida certa, pode ser útil na resistência à deformação permanente. Segundo a resolução ANP no 19/2005 [25] a perda de massa de ligantes puros é de no máximo 0,5\%, desta forma, todos os ligantes atenderam a este critério.

Pode-se observar que a adição de lignina reduziu a penetração do ligante, sob as condições normal e envelhecida, o que significa um aumento de rigidez. Este aumento de rigidez indica um aumento da resistência à deformação. O limite estabelecido pela resolução ANP no 19/2005 [25] para esse parâmetro é o intervalo de 50 a 70 décimos de milímetro. $\mathrm{O}$ resultado do ligante sem adição de lignina atendeu ao critério da especificação da ANP. Contudo, os ligantes modificados não se enquadraram no intervalo, pois, ocasionaram a redução da penetração além do previsto para o ligante puro, porém sem comprometer sua utilização.

Comparando os resultados antes e após o envelhecimento, obteve-se a penetração retida, que significa o quanto a penetração após o envelhecimento representa da penetração na condição normal. Esse dado é de suma importância para verificar a sensibilidade do ligante ao envelhecimento e para isso a resolução ANP no 19/2005 [25] define o mínimo de 55\% para esse parâmetro. Assim, maiores valores para a porcentagem de penetração retida (PPR) indicam menor sensibilidade ao envelhecimento e vice-versa.

Cravo [1] em sua pesquisa utilizando lignina proveniente do licor negro da produção de etanol de segunda geração (2G) e outra comercial altamente pura e associando-as a um CAP 50/70 em teores de 1,5\% e $15 \%$ de seu peso, respectivamente, também confirma que o acréscimo dos dois tipos de lignina ao ligante aumentou a consistência, reduzindo a penetração da mistura ligante/aditivo.

Botaro et al. [27] explica que a incorporação de um grande número de anéis aromáticos presentes na estrutura da lignina, contribui para aumentar a rigidez do ligante. $\mathrm{O}$ autor estudou a adição de $1 \%$ a $6 \%$ de lignina extraída do bagaço da cana-de-açúcar pelo processo organossolv etanol/água na obtenção de blendas de CAP20 e os resultados mostraram uma tendência de diminuição da penetração em função do aumento da concentração da lignina.

Para o ponto de amolecimento, verificou-se que houve uma tendência de aumento com o acréscimo de lignina ao ligante. Isto é vantajoso, pois quanto maior o ponto de amolecimento, menor é a ocorrência de deformações e menos sensível torna-se o ligante à temperatura, mantendo suas propriedades até temperaturas mais elevadas, fato que pode ser observado com o notável acréscimo em $8,75^{\circ} \mathrm{C}$ no ligante com $9 \%$ de lignina comparado ao ligante puro.

A menor variação dos pontos de amolecimentos observada nos ligantes modificados por adição de lignina em relação ao ligante puro reflete a influência da mesma na resistência ao envelhecimento.

Para o Índice de susceptibilidade térmica, observou-se que todos os ligantes atenderam à especificação e o acréscimo de lignina manteve o ligante numa faixa mais próxima de zero, o que indica que o ligante tornou-se menos susceptível ao efeito da variação de temperatura. Segundo Bernucci [28] IST 
maiores que $(1,0)$ indicam asfaltos oxidados e menores que $(-2,0)$ asfaltos muito sensíveis à variação de temperatura.

Para a recuperação elástica do ligante, verificou-se que adição de lignina atribuiu uma melhoria na característica elástica, embora, os resultados não sejam significativos comparados a um polímero elastomérico.

Em relação à viscosidade, ao considerar, inicialmente, os ligantes na condição não envelhecida, observa-se um aumento da viscosidade com o acréscimo dos teores de lignina em relação ao ligante puro, principalmente nas temperaturas mais inferiores de ensaio $\left(135^{\circ} \mathrm{C}<\mathrm{T}<150^{\circ} \mathrm{C}\right)$, com um destaque maior para o ligante com $9 \%$, pois os ligantes com os demais teores não apresentaram variação significante entre eles.

Nota-se que com o aumento da temperatura, as viscosidades dos ligantes modificados por adição de lignina convergiram para praticamente o mesmo valor em $150^{\circ} \mathrm{C}$ e em seguida mantiveram-se constantes entre si, mas tendendo a retornar ao valor da viscosidade do ligante puro em $177^{\circ} \mathrm{C}$. Esse comportamento é evidenciado pela maior inclinação das curvas dos ligantes com adição de lignina e demonstra uma maior variabilidade da viscosidade com a temperatura.

Comparando os ligantes antes e após RTFO, observa-se que o envelhecimento causou o aumento da viscosidade como era previsto. Além disso, percebe-se uma mudança maior na viscosidade do ligante puro em relação aos modificados por adição de lignina, o que indica mais uma vez a resistência ao envelhecimento devido a adição da lignina no ligante.

Quanto à resolução ANP $\mathrm{n}^{\circ}$ 19/2005 [25], os valores das viscosidades do ligante puro, e consequentemente dos modificados por adição de lignina, atenderam aos valores mínimos $\left(274 \mathrm{cP}-135^{\circ} \mathrm{C}\right.$ e $\left.112 \mathrm{cP}-150^{\circ} \mathrm{C}\right)$ e intervalo $\left(28-114 \mathrm{cP}-177^{\circ} \mathrm{C}\right)$ da especificação com suas respectivas temperaturas. Além disso, segundo a especificação SUPERPAVE, o limite máximo de $3 \mathrm{~Pa}$.s na temperatura de $135^{\circ} \mathrm{C}$ para a viscosidade também foi atendido em todos os resultados. Cabendo salientar que $1 \mathrm{cP}=0,001$ Pa.s.

Em relação à temperatura de usinagem, determinada a partir do intervalo de viscosidade compreendido entre $(170 \pm 20) \mathrm{cP}$, obteve-se para o ligante puro valores numa faixa de $157 \pm 3^{\circ} \mathrm{C}$, enquanto para os ligantes modificados os valores ficaram em torno de $160 \pm 3^{\circ} \mathrm{C}$. Levando-se em consideração os pontos médios dessas temperaturas, esses três graus de diferença não são significativos e não alteram de certa forma, a trabalhabilidade da mistura, o que mostra que o aumento da viscosidade com a adição de lignina não foi excessiva.

Para o grau de desempenho dos ligantes, verificou-se que apesar dos teores de lignina terem elevado o grau de desempenho em um nível na condição não envelhecida, por ocasião do envelhecimento o comportamento se mostrou invariável em relação ao ligante puro. Optou-se por determinar apenas o PG para a faixa de altas temperaturas, PG máximo, por uma questão de clima regional, visto que os pavimentos no território brasileiro dificilmente trabalharão em temperaturas abaixo de zero.

Analisando as figuras 9 e 10, pode-se comparar diretamente o parâmetro $\mathrm{G}^{*} / \mathrm{sen} \delta$, assim como os módulos complexos $\mathrm{G}^{*}$, antes e após RTFO, pois o comportamento do gráfico apenas com o $\mathrm{G}^{*}$ é muito semelhante ao ilustrado nestas figuras, devido ao sen $\delta$ ser bem próximo de 1 e não alterar significativamente o resultado. Percebe-se que o efeito do envelhecimento levou a uma variação maior na rigidez do ligante puro, mostrando uma maior resistência ao envelhecimento para os teores de $3 \%$ e $6 \%$ de lignina, e de forma mais moderada para o teor de $9 \%$ de lignina, para os quais houve menor variação. Analisando o parâmetro $\mathrm{G}^{*} /$ sen $\delta$ antes do RTFO, a adição de lignina promoveu o aumento da consistência do ligante puro, consequentemente a sua rigidez e resistência à deformação, observa-se ainda na figura 10, que o ligante com teor de $9 \%$ de lignina se sobressai aos demais ligantes podendo-se inferir que este teor atribuiu uma maior resistência ao material. No entanto, esse comportamento pode ser justificado pela interação partículapartícula do polímero disperso e não necessariamente à melhoria da propriedade do ligante em si.

Os ângulos de fase obtidos para o ligante modificado por adição de lignina antes do envelhecimento a curto prazo foram inferiores quando comparados aos resultados alcançados para o ligante puro. Após envelhecimento a curto prazo, verificou-se que as curvas que representam os teores de $6 \%$ e $9 \%$ de lignina até $52^{\circ} \mathrm{C}$ mostraram-se com $\delta$ inferiores à curva do ligante puro, passando a partir desta temperatura a se comportar de maneira idêntica. Notavelmente, a curva referente a $3 \%$ de lignina divergiu bastante das demais e mostrou uma redução maior do ângulo de fase, indicando uma leve melhora na resposta elástica, pois, sabese que a proximidade dos ângulos com $90^{\circ}$ indica ligantes viscosos e praticamente sem elasticidade.

Avaliando o percentual de recuperação percebe-se que os resultados não foram expressivos devido à reduzida recuperação que os ligantes apresentaram tanto a $100 \mathrm{~Pa}$ quanto a $3200 \mathrm{~Pa}$. Isso pode ser até de certa forma justificado pela natureza do próprio teste ao considerar a temperatura máxima do PG do ligante, que é a situação mais desfavorável, e a qual eleva o material a uma condição mais difícil de ter o retorno elástico detectado, pela característica fluída que o ligante passa a ter, mas também pela maneira como se comportou os ângulos de fase apresentados, os quais indicaram que o ligante manteve-se sem característica elástica significante pelo acréscimo de lignina no mesmo. 
Para os resultados da deformação não-recuperável, observa-se um valor muito elevado de deformação para o ligante puro, ficando inclusive fora da classificação prevista pela AASHTO M320 [29], a qual limita até $4,0 \mathrm{kPa}^{-1}$ a deformação para o ligante ser enquadrado como ideal para um tráfego padrão com até 10.000 milhões de passadas de um eixo padrão. Pela classificação, a deformação cujo valor encontre-se entre 2,0 e 4,0 $\mathrm{kPa}^{-1}$ são para um tráfego tipo padrão e como pôde-se observar os ligantes modificados por adição de lignina atenderam a esse intervalo, obtendo-se o melhor resultado para o teor de $9 \%\left(2,4 \mathrm{kPa}^{-1}\right)$.

Conforme apresentado na tabela 2, pode-se observar ainda que o Jnr dif (\%), o qual refere-se à diferença entre as compliâncias não-recuperáveis a $100 \mathrm{~Pa}$ e a 3.200 Pa e cujo limite não deve ser superior a $75 \%$ para garantir que o material não seja excessivamente sensível a mudanças nos níveis de tensão, conforme menciona [5], embasada pela AASHTO MP19 [30]. Assim, os percentuais obtidos apresentaram valores bastante inferiores ao limite mencionado, revelando-se ligantes mais resistentes às solicitações à medida que acrescenta-se teores de lignina mais elevados.

\section{CONCLUSÕES}

A análise dos resultados dos ensaios empíricos mostrou que a presença de lignina no ligante contribuiu positivamente na resistência à deformação, mas principalmente na resistência ao envelhecimento do material comparado ao ligante puro. $\mathrm{O}$ aumento da resistência à deformação foi verificada com a redução da penetração e consequente aumento da consistência, assim como no aumento do ponto de amolecimento e da recuperação elástica, o qual fundamentou ainda mais essa afirmação. Já o aumento da resistência ao envelhecimento foi notado pelas menores variações dessas mesmas propriedades antes e após RTFO nos ligantes modificados. Outro fator observado que agregou viabilidade à utilização da lignina foi a menor sensibilidade à variação de temperatura, que pôde ser confirmado pelo IST mais próximo a zero.

Para viscosidade, o maior aumento da viscosidade foi proporcionado pelo teor de $9 \%$ de lignina na temperatura de $135^{\circ} \mathrm{C}$ e percentualmente esse aumento foi de $35 \%$ em relação ao ligante puro. Esse aumento na viscosidade causou evidentemente um aumento também na temperatura de usinagem, em $3^{\circ} \mathrm{C}$, se considerado o ponto médio das faixas de temperaturas anteriormente determinadas para o ligante puro (157 $\left.\pm 3^{\circ} \mathrm{C}\right)$ e para os modificados $\left(160 \pm 3^{\circ} \mathrm{C}\right)$. No entanto, esse valor é considerado insignificante, justificado até mesmo pela norma [19], que define o intervalo conveniente para a temperatura do ligante ser trabalhado na mistura entre $107^{\circ} \mathrm{C}$ a $177^{\circ} \mathrm{C}$.

Na varredura de temperatura realizada no DSR, os PG dos ligantes modificados não foram alterados após o envelhecimento em relação ao ligante puro. Entretanto, ao menos a lignina manteve a mesma faixa de temperatura de atuação e manutenção das propriedades do ligante, não comprometendo seu desempenho. Já os módulos complexos $\mathrm{G}^{*}$ dos ligantes foram modificados com a presença da lignina, aumentando sua rigidez e contribuindo para a resistência à deformação permanente, verificada através do parâmetro $\mathrm{G}^{*} / \operatorname{sen} \delta$. Antes do envelhecimento, este parâmetro aumentou em relação ao ligante puro, mas praticamente não apresentou variação entre os três teores. Porém, para o teor de $9 \%$ verificou-se uma diferença mais acentuada após o envelhecimento. Para o $\mathrm{G}^{*} / \mathrm{sen} \delta$ do ligante puro, verificou-se que este variou mais antes e após RTFO que os modificados, os quais permaneceram mais resistentes ao efeito do envelhecimento.

Quanto ao ângulo de fase, os resultados não apontam consideravelmente a propriedade de elasticidade pela adição de lignina no ligante e esse fato pôde ser comprovado com os resultados do MSCR, através do percentual de recuperação (\%Rec), que não se mostraram expressivos. Contudo, quando se verifica a deformação não recuperável (Jnr) dos ligantes modificados, nota-se um desempenho bem melhor que o ligante puro, inclusive enquadrando-os numa faixa de volume de tráfego superior (tráfego padrão) ao apresentado por aquele, com destaque para o teor de $9 \%$ de lignina.

Portanto, dentre os resultados desta pesquisa, o teor ótimo de lignina a ser empregado em ligantes convencionais a fim de melhorar seu desempenho foi o de $9 \%$, embora os demais teores testados $(3 \%$ e $6 \%)$ também tenham resultado na modificação das propriedades reológicas do ligante puro e mostrarem-se adequadas para utilização do material em campo.

Pode-se concluir que a utilização da lignina é viável por melhorar as propriedades reológicas do ligante asfáltico. Considerando aspectos ambientais, pode ser uma alternativa para evitar o descarte indiscriminado desse resíduo da indústria de papel e celulose. Finalmente, do ponto de vista econômico, demonstrou ser possível a substituição parcial do ligante com o uso do teor de $9 \%$ desse material.

\section{AGRADECIMENTOS}

Ao Programa de Pós-Graduação em Engenharia Civil e Ambiental da Universidade Federal de Campina Grande pela oportunidade oferecida na realização do Mestrado e a todos que direta ou indiretamente contribuíram para conclusão deste trabalho. 


\section{BIBLIOGRAFIA}

[1] CRAVO, M. C. C. Efeitos do envelhecimento térmico e fotoquímico em ligantes asfálticos, mástique e matriz de agregados finos, Tese de D.Sc., Universidade Federal do Rio de Janeiro, Rio de Janeiro, 2016.

[2] LUCENA, M. C. C. Caracterização química e reológica de asfaltos modificados por polímeros. 2005. 163f. Tese de D.Sc., Universidade Federal do Ceará, Fortaleza, 2005.

[3] BRINGEL, R. M. Estudo químico e reológico de ligantes asfálticos modificados por polímeros e aditivos. 2007. 174 f. Dissertação de M.Sc., Universidade Federal do Ceará, Fortaleza, 2007.

[4] LIMA, C. S., SOARES, J. B., TOMÉ, L. G. A. Estudo das propriedades químicas e reológicas do ligante asfalto-borracha, In: Trabalho apresentado ao $3^{\circ}$ Congresso Brasileiro de P\&D em Petróleo e Gás, Salvador, 2004.

[5] SOBREIRO, F. P. Efeito da adição de ácidos fosfóricos no comportamento reológico de ligantes asfálticos puros e modificados com copolimero SBS, Tese de D.Sc., São Carlos, 2014.

[6] NASCIMENTO, T. C. B. Efeito dos envelhecimentos termo-oxidativo e foto-oxidativo sobre propriedades reológicas de ligantes asfálticos modificados, Dissertação de M.Sc., Universidade de São Paulo, São Carlos, 2015.

[7] SOUZA, L. J. S. Estudo das propriedades mecânicas de misturas asfálticas com cimento asfáltico de petróleo modificado com óleo de mamona, Dissertação de M.Sc., Universidade Federal de Campina Grande, Campina Grande, 2012.

[8] LENI, L. F. M., CHACUR, M., NASCIMENTO, L. A. H., et al., The use of vegetal products as asphalt cement modifier. 5th Eurasphalt \& Eurobitume Congress, Istanbul, 2012.

[9] SILVEIRA, I. V. S. Propriedades reológicas sob altas temperaturas de ligantes asfálticos modificados com óleo da moringa. $43^{\mathrm{a}} \mathrm{RAPv}$ - Reunião Anual de Pavimentação e $17^{\circ}$ ENACOR - Encontro Nacional de Conservação Rodoviária, Maceió, 2014.

[10] CAVAlCANTE, F. P. Efeito da adição dos óleos de ricinus communis e linus usitatissimum nas propriedades reológicas do cimento Asfáltico de petróleo puro e modificado, Tese de D.Sc., Universidade Federal de Campina Grande, Campina Grande, 2016.

[11] CASTRO, H. F. Papel e Celulose. 2009. 30 f. Apostila 4 (Disciplina Processos Químicos Industriais II). Universidade de São Paulo, Escola de Engenharia de Lorena, Lorena, 2009.

[12] LONGUE JUNIOR, D., COLODETTE, J. L. "Importância e versatilidade da madeira de eucalipto para a indústria de base florestal", Pesquisa Florestal Brasileira, Colombo, v. 33, n. 76, p. 429-438 out./dez. 2013.

[13] PILÓ-VELOSO, D., NASCIMENTO, E. A., MORAIS, S. A. L. Isolamento e análise estrutural de ligninas. Química Nova, v. 16, n. 5, p. 435-448, 1993.

[14] OLIVEIRA, F. C. Oxidação de lignina proveniente de resíduos lignocelulósicos agroindustriais para obtenção de compostos químicos aromáticos de maior valor agregado, Tese de D.Sc., Escola de Engenharia de Lorena, Universidade de São Paulo, Lorena, 2015.

[15] LUCENA, M. C. C., SOARES, J. B., SOARES, S. A., et al., "Reologia de asfaltos brasileiros puros e modificados por SBS", In: XVII Congresso de Pesquisa e Ensino em Transportes, ANPET, Rio de Janeiro, 2004a.

[16] MOTHÉ, M. G. Estudo do Comportamento de Ligantes Asfálticos por Reologia e Análise Térmica. 2009. 204 f. Dissertação de M.Sc., Universidade Federal do Rio de Janeiro, Rio de Janeiro, 2009.

[17] D’ANTONA, D. M. G., FROTA, C. A. "Estudo de Misturas Asfálticas com Ligante Modificado pelo Polímero EVA para Pavimentos Urbanos de Manaus - AM", Polímeros, v. 21, p. 13-18, 2011.

[18] DEPARTAMENTO NACIONAL DE INFRAESTRUTURA E TRANSPORTE - DNIT - ME 155/2010. Material asfáltico - determinação da penetração, Rio de Janeiro, 2010.

[19] DEPARTAMENTO NACIONAL DE INFRAESTRUTURA E TRANSPORTE - DNIT-ME 131/2010. Materiais Asfálticos - Determinação do ponto de amolecimento - Método do Anel e Bola, Rio de Janeiro, 2010.

[20] DEPARTAMENTO NACIONAL DE INFRAESTRUTURA E TRANSPORTE - DNIT-ME 130/2010. Determinação da recuperação elástica de materiais asfálticos pelo ductilômetro, Rio de Janeiro, 2010.

[21] ASSOCIAÇÃO BRASILEIRA DE NORMAS TÉCNICAS. NBR 15184: Materiais Betuminosos Determinação da viscosidade em temperaturas elevadas usando viscosímetro rotacional. São Paulo, 2004. 
[22] AMERICAN SOCIETY FOR TESTING MATERIALS - ASTM D4402: Standard Test Method for Viscosity Determination of Asphalt at Elevated Temperatures Using a Rotational Viscometer. West Conshohocken, PA, 2015.

[23] AMERICAN SOCIETY FOR TESTING MATERIALS - ASTM D 6373: Standard Specification for Performance Graded Asphalt Binder. West Conshohocken, PA, 2015.

[24] AMERICAN SOCIETY FOR TESTING MATERIALS - ASTM D 7405: Standard Test Method for Multiple Stress Creep and Recovery (MSCR) of Asphalt Binder Using a Dynamic Shear Rheometer. West Conshohocken, PA, 2015.

[25] BRASIL. Agência Nacional do Petróleo, Gás Natural e Biocombustível (ANP). Resolução no 19 de 11 de julho de 2005. Estabelece as especificações dos cimentos asfálticos de petróleo comercializados pelos diversos agentes econômicos em todo o território nacional. Rio de Janeiro, 2005.

[26] GAMA, D. A. Efeito da adição de polímeros reativo, não-reativo e ácido polifosfórico e suas combinações nas propriedades de ligantes asfálticos, Tese de D.Sc., Universidade Federal de Campina Grande, Campina Grande, 2016.

[27] BOTARO, V. R., CASTRO, S. R., JUNIOR, F. R., et al., "Obtenção e caracterização de blendas de asfalto CAP 20, modificado com poliestireno reciclado, resíduos de pneu e lignina organossolve", REM: Revista Escola de Minas, Ouro Preto, v. 59, n. 1, p. 117-122, jan./mar. 2006.

[28] BERnUCCI, L. B., MOTTA, L. M. G., CERATTI, J. A. P., et al., Pavimentação Asfáltica: Formação Básica para Engenheiros. Rio de Janeiro, PETROBRAS, ABEDA, 2008.

[29] AMERICAN ASSOCIATION OF STATE HIGHWAY AND TRANSPORTATION OFFICALS AASHTO M320: Standard Specification for Performance-Graded Asphalt Binder. Washington, D. C., 2016.

[30] AMERICAN ASSOCIATION OF STATE HIGHWAY AND TRANSPORTATION OFFICALS AASHTO MP19: Standard Specification for Performance-Graded Asphalt Binder Using Multiple Stress Creep Recovery (MSCR) Test. Washington, D. C., 2010. 